\title{
Symptom cluster, healthcare use and mortality in patients with severe chronic obstructive pulmonary disease
}

\author{
Soo Kyung Park and Janet L Larson
}

\begin{abstract}
Aims and objectives. To examine how subgroups of patients with chronic obstructive pulmonary disease, identified by ratings of symptoms (dyspnoea, anxiety, depression and fatigue), affect healthcare use and mortality.

Background. People with chronic obstructive pulmonary disease often experience multiple symptoms. The importance of multiple symptoms and symptom clusters has received increased attention. However, little is known about symptom clusters and their effect on healthcare use and mortality in this population.

Design. Descriptive cross-sectional study.

Methods. This secondary data analysis used data from the National Emphysema Treatment Trial. Participants $(n=597)$ had severe chronic obstructive pulmonary disease. Descriptive and inferential statistics were used to analyse the data that were drawn from structured interviews, questionnaires and clinical measures.

Results. Three subgroup clusters emerged based on four symptom ratings. Mean age, proportion with higher education, proportion using oxygen, disease severity, exercise capacity and quality of life differed significantly between subgroups. Participants with high levels of symptoms used healthcare services more and were more likely to have died at the five-year follow-up than those with low levels of symptoms. Symptom cluster subgroups had more significant relationship with mortality than single symptoms.

Conclusion. Patients with high levels of symptoms require greater clinical attention.

Relevance to clinical practice. Understanding subgroups of patients, based on symptom ratings and their adverse effect on outcomes, may enable healthcare providers to assess multiple symptoms and identify subgroups of patients at risk of increased healthcare use and mortality. Targeting modifiable symptoms within the cluster may be more beneficial than focusing on a single symptom for certain health-related outcome.
\end{abstract}

Key words: chronic obstructive pulmonary disease, healthcare use, mortality, National Emphysema Treatment Trial, symptoms

Accepted for publication: 10 November 2013

Authors: Soo Kyung Park, PhD, RN, Assistant Professor, School of Nursing, Korea University, Seoul, Korea; Janet L Larson, PhD, RN, Professor, School of Nursing, University of Michigan, Ann Arbor, MI, USA
What does this paper contribute to the wider global clinical community?

- Patients with high levels of symptoms require greater clinical attention.

- Targeting modifiable symptoms within the cluster may be more beneficial than focusing on a single symptom to improve survival in people with chronic obstructive pulmonary disease (COPD).
Correspondence: Soo Kyung Park, Assistant Professor, School of Nursing, Korea University, 145 Anam-Ro, Seongbuk-gu, Seoul, Korea. Telephone: +821098869837.

E-mail: sookyung.park7@gmail.com 


\section{Introduction}

In 2008, chronic obstructive pulmonary disease (COPD) was ranked as the third leading cause of death in the USA (Miniño et al. 2010). Mortality from COPD is still substantial, although the mortality rate in people with COPD has declined since 1999 (Ford et al. 2013). Overall mortality from COPD was reported to be $44 \%$ and, in severe cases of the disease, to be $71 \%$ in a 22 -year cohort study that was conducted in the USA (Mannino et al. 2003). Another 20-year cohort study, conducted in Sweden, reported 54\% overall mortality in patients with COPD and $81 \%$ in those with severe disease (Lundbäck et al. 2009).

People with COPD use substantial medical resources at great cost. In 2010, COPD care was projected to cost $\$ 49.9$ billion, more than a quarter of which was attributed to hospital care alone (National Institutes of Health, National Heart, Lung, \& Blood Institute 2013). In 2006, COPD accounted for 672,000 hospital admissions (American Lung Association 2013), which represents $52-70 \%$ of direct per patient costs (Foster et al. 2006). Besides treatment costs, hospital admissions have a negative effect on the survival rates of patients with COPD (Almagro et al. 2002).

Research studies of people with COPD have focused mainly on single symptoms. However, people with COPD rarely experience just one symptom in the course of their disease. Rather, they experience multiple symptoms that adversely affect their quality of life and functional status (Blinderman et al. 2009, Park et al. 2012). The concept of symptom clusters, that is, two or more related concurrent symptoms, offers a new approach to symptom assessment and management (Kim et al. 2005). It is now known that certain symptom clusters and high symptom burden can affect clinical outcomes, such as functional status, quality of life or level of physical activity in people with a variety of chronic diseases (Miaskowski et al. 2006, Motl \& McAuley 2009, Aktas et al. 2010). Furthermore, healthcare use and mortality have been examined in the literature as an outcome of symptom clusters in people with acute coronary syndrome, heart failure and a history of lung cancer (Lee et al. 2010, Riegel et al. 2010, Cheville et al. 2011, Hwang et al. 2012). These studies found that people with certain symptom clusters had significantly higher mortality rates (Riegel et al. 2010, Hwang et al. 2012). One study, however, found no association between visits to an emergency department (ED) and symptom clusters in people with acute coronary syndrome (Riegel et al. 2010).

Overall, little is known about the relationship between symptom clusters and healthcare use and mortality in people with COPD. Worsening symptoms are main reason why patients with COPD seek treatment or hospital care. One study has shown that dyspnoea, the main symptom experienced by people with COPD, was a stronger predictor of mortality than disease severity (Nishimura et al. 2002). Thus, the effect of symptom clusters on healthcare use and mortality in people with COPD should be examined: Symptom clusters could be a modifiable factor to decrease healthcare use and morality and may be a stronger predictor of adverse outcomes than single symptoms. In this study, we formed subgroups based on four symptoms (dyspnoea, anxiety, depression and fatigue) that are commonly experienced by people with COPD and examined their effect on healthcare use and mortality. By this approach, healthcare providers will be better able to identify patients who are likely to use more healthcare services and are at risk of higher mortality.

\section{Background/Literature review}

\section{Symptoms and healthcare use in patients with COPD}

In the past, researchers have examined the relationship between single symptoms and healthcare use in people with COPD. Dyspnoea has been associated with COPD-related hospital admissions (Schembri et al. 2009) and has also independently predicted exacerbation-related hospital admissions and visits to the ED (Fan et al. 2007). Anxiety was related to relapse within one month after emergency treatment in patients with asthma or COPD (Dahlén \& Janson 2002). However, another study found no association between anxiety and hospital admission in patients with severe COPD (Fan et al. 2007). Depression was found to be an independent predictor of hospital admissions for acute exacerbation at follow-up one year poststudy (Papaioannou et al. 2013). Dahlén and Janson (2002), who also examined ED patients with asthma or COPD, found that depression was related to relapse within one month after emergency treatment. In contrast, another study found no relationship between depression and hospital admission in patients with severe COPD (Fan et al. 2007). Ng et al. (2007) also found that depression was not significantly associated with hospital readmission in an adjusted model. Finally, the literature contains no information on the relationship between fatigue and healthcare use in people with COPD.

\section{Symptoms and mortality in patients with COPD}

Past studies of people with COPD have reported the relationship of single symptoms with mortality. Dyspnoea has been found to be predictive of survival in patients with COPD (Nishimura et al. 2002, Esteban et al. 2008, 
Schembri et al. 2009) and to be superior to forced expiratory volume in one second (FEV1) in predicting death (Nishimura et al. 2002). All-cause mortality and risks of cardiovascular mortality were significantly increased among patients with severe dyspnoea (Figarska et al. 2012). Unlike dyspnoea, anxiety has not been associated with mortality in the literature (Fan et al. 2007, Ng et al. 2007). Reports on the relationship between depression and mortality are in conflict. Several studies have reported a significant association between depression and an increased risk of mortality (Fan et al. 2007, Ng et al. 2007, de Voogd et al. 2009, Papaioannou et al. 2013). Yet, other studies have reported just the opposite (Yohannes et al. 2002, 2005, Stage et al. 2005). As for fatigue, little is known about relationship between fatigue and mortality in people with COPD. Overall, no studies have examined how symptom clusters affect healthcare use and mortality in people with COPD.

\section{Purpose}

The purpose of this study was to determine how subgroups of patients with COPD, identified by their ratings of symptoms (dyspnoea, anxiety, depression and fatigue), differed on healthcare use and mortality.

\section{Methods}

\section{Design}

Data from the National Emphysema Treatment Trial (NETT) was used for this cross-sectional study. The NETT study was conducted by the Centers for Medicare and Medicaid Services, the National Institutes of Health and the Agency for Healthcare Research and Quality. Its design and method have been described previously (National Emphysema Treatment Trial Research Group 1999, Fishman et al. 2003). The purpose of the NETT, an original randomised controlled trial, was to evaluate the safety and effectiveness of lung volume reduction surgery for people with emphysema.

\section{Sample, settings and procedures}

Patients were recruited for the NETT by self-referral or they were referred by their physician. After the patients' history and clinical information were reviewed for eligibility, those without contraindications to participation were invited for testing. In all, 3777 patients were screened for the NETT from 1998-2002 (National Emphysema Treatment Trial Research Group 2003). To be included in the study, individuals were required to have: (1) radiological evidence of bilateral emphysema; (2) severe airflow obstruction and hyperinflation; and (3) participation in pulmonary rehabilitation and attainment of preset performance goals (National Emphysema Treatment Trial Research Group 1999). Individuals were excluded if they exhibited characteristics that placed them at risk of perioperative morbidity or mortality such as previous lung transplantation or congestive heart failure within six months (National Emphysema Treatment Trial Research Group 1999). All participants completed 4-10 weeks of pulmonary rehabilitation before randomisation and six sessions of rehabilitation after randomisation. A total of 1218 individuals underwent randomisation. All participants at the 17 NETT clinics were randomly assigned to either usual medical therapy $(n=610)$ or usual medical therapy plus lung volume reduction surgery $(n=608)$.

Baseline measurements were taken before randomisation. Various measures were recollected at six months, at 12 months and yearly thereafter postrandomisation. The NETT's primary outcomes were mortality and maximum exercise capacity two years after randomisation. For our analysis, we included participants in the medical therapy group $(n=610)$ who were aged $52-79$ because the data set did not provide ages for patients younger than 52 and older than 79. Only those patients who had data for all variables were included. We used baseline data for all study variables except outcome variables. The NETT was approved by each clinic's institutional review board, and informed consent was obtained from each participant.

\section{Instruments}

\section{Dyspnoea}

The University of California, San Diego, Shortness of Breath Questionnaire (SOBQ) was used to measure dyspnoea. This instrument, which comprises 24 items, measures shortness of breath associated with 21 daily activities and limitations in daily life. Of the 24 items, we used 21 for our analysis. Participants answered each question on a scale of zero ('none at all') to five ('maximal or unable to do because of breathlessness'). Cumulative scores could range from 0 ('best')-105 ('worst'). This instrument's internal consistency $(\alpha=0.96)$ and concurrent validity with FEV1 $(r=-0.50)$ have been reported in the literature (Eakin et al. 1998). Internal consistency for our study was Cronbach's alpha $=0.94$.

Anxiety

Anxiety was assessed with the state anxiety component of the State-Trait Anxiety Inventory (STAI). This instrument 
consists of 20 questions on a four-point scale: 1 ('almost never'), 2 ('sometimes'), 3 ('often') and 4 ('almost always') (Spielberger et al. 1983). Cumulative scores could range from 20-80. Higher scores indicated higher levels of anxiety. Test-retest reliability and concurrent validity have been reported in the literature (Spielberger et al. 1983).

\section{Depression}

Depression was evaluated with the Beck Depression Inventory (BDI), which comprises 21 items (Beck \& Steer 1993). In response to each item, participants were asked to select one of four sentences that reflected how they felt over the past two weeks. Responses were scored on a scale of $0-3$. Cumulative scores could range from 0-63. Higher scores indicated a deeper level of depression. Test-retest reliability $(r=0.95)$ has been reported (Fountoulakis et al. 2007). Concurrent validity with the Center for Epidemiologic Studies' Depression Scale has been reported (Kalichman et al. 2000). Internal consistency for this study was Cronbach's alpha $=0.70$.

\section{Fatigue}

The vitality subscale of the Medical Outcomes Study 36-Item Short-Form Health Survey (MOS-36) was used to assess fatigue. This subscale has been used to measure fatigue in people with other chronic diseases (Hewlett et al. 2011, Harel et al. 2012). Participants were asked to respond to four questions about fatigue during the past four weeks such as feeling full of pep, worn out, tired and having a lot of energy. Options for response ranged from 1 ('all the time')-6 ('none of the time'). The vitality subscale was then calculated, with scores ranging from 0-100. Higher scores meant participants had more vitality. Testretest reliability $(r=0.92)$ has been reported for a fourweek interval in people with osteoarthritis (Söderman \& Malchau 2000). The concurrent validity of the MOS-36 vitality subscale with the Functional Assessment of Chronic Illness Therapy Scale has been reported $(r=0.65)$ (Harel et al. 2012). Internal consistency for the vitality subscale in this study was Cronbach's alpha $=0.80$.

\section{Outcome variables}

\section{Healthcare use}

Healthcare use was assessed by telephone interview. Participants were asked to indicate: (1) the number of nights they spent in a hospital or other acute care facility; (2) the number of nights they spent in a rehabilitation hospital, nursing home or other nonacute care facility; (3) the number of visits to an $\mathrm{ED}$, triage or urgent care facility; and (4) the number of visits to a physician assistant, nurse or outpatient clinic in the last month. The questions addressed all healthcare use, not just care for COPD. This information was collected at 1, 2, 4, 8 and 10 months after randomisation occurred. The data collected at these time periods were included in our analysis.

\section{Mortality}

Vital status was drawn from clinical reports through 31 May 2008 and matched to the Social Security Administration's Master Death File. For our study, we analysed data for five-year mortality.

\section{Other covariates}

Demographic and clinical data

Information about age, gender, level of education, marital status, income, smoking history and current oxygen use at rest and during sleep was obtained by interview.

\section{Pulmonary function testing}

Spirometry was performed with participants seated. The NETT followed American Thoracic Society guidelines when conducting pulmonary function tests and single-breath diffusion capacity (American Thoracic Society 1995a,b). Predicted values for spirometry and diffusion capacity were used for this analysis (Crapo \& Morris 1981, Crapo et al. 1981). Partial pressure of oxygen $\left(\mathrm{PaO}_{2}\right)$ and partial pressure of carbon dioxide $\left(\mathrm{PaCO}_{2}\right)$ results, which were collected while participants breathed room air at rest, were also used for this analysis.

\section{Exercise capacity}

Exercise capacity was measured by an electromagnetically braked cycle ergometer. Participants performed unloaded pedalling for three minutes at any cadence between 40-70 revolutions/minute (rpm); after 10 minutes of rest, the load was increased at a rate of $5-10 \mathrm{~W}$ every minute while participants breathed $30 \%$ oxygen (National Emphysema Treatment Trial Research Group 2003). The test was terminated when the cadence dropped below $40 \mathrm{rpm}$ or when a staff member terminated the test for safety. Peak workload, maximum watt on the cycle, was used for this analysis. Various physiological measures such as breathlessness and leg muscle fatigue were assessed during the test. Test-retest reliability of oxygen consumption during a cycle ergometer test has been reported in people with COPD (reliability coefficient $=0.97)($ Covey et al. 1999).

Quality of life

Quality of life was measured by the MOS-36. This instrument, which consists of 36 items, measures eight compo- 
nents of health: physical functioning, role-physical, bodily pain, general health perception, vitality, social functioning, role-emotional and mental health. The mental component subscale and physical component subscale were used for this analysis. The range for each subscale is $0-100$. Higher scores signified better health. Reliability coefficients of the MOS-36 have been reported (0.65-0.94) (McHorney et al. 1994). Further, comparisons of MOS-36 scores among different populations have affirmed the instrument's construct validity (McHorney et al. 1993). Cronbach's alpha was 0.67 for the physical component subscale and 0.63 for the mental component subscale in this study.

\section{Data analysis}

SPSS, version 20.0 (IBM, Armonk, NY, USA) was used to analyse all data. All continuous variables were expressed as mean and standard deviation. Categorical variables were presented as percentage and frequency. Descriptive statistics were used to describe sample characteristics and study variables. Symptom scores from the University of California, San Diego, Shortness of Breath Questionnaire (UCSD), Spielberger State-Trait Anxiety Inventory (STAI), Beck Depression Inventory (BDI) and Medical Outcomes Study 36-Item (MOS-36) Short-Form Health Survey were standardised for our cluster analysis to equalise the effect of the instruments' different scale lengths. An agglomerative hierarchical cluster analysis was performed with squared Euclidean distances used in the proximities matrix, and Ward's method used as the clustering method. Agglomerative hierarchical clustering begins with each symptom as a separate cluster and then merges symptoms into a larger cluster. Ward's method was chosen because it is considered to be superior in decreasing misclassification of observations (Jain et al. 1986). Our decision on the appropriate number of cluster solutions was based on dendrogram and incremental changes in agglomeration coefficients (Ketchen \& Shook 1996).

One-way analysis of variance (ANOVA) or chi-square tests were used to determine whether significant differences existed among the subgroups of participants in demographic and clinical characteristics, symptom scores and outcome measures. Post hoc analyses were conducted using the Bonferroni procedure to control the overall alpha level of the six possible pairwise contrasts at 0.05.

Univariate and multivariate Poisson regression analyses were used to examine how different subgroups and single symptoms predict hospital outcomes during 10 months of follow-up. The results were presented as incidence rate ratio with $95 \%$ CI. Single symptoms were divided into three groups to compare their effect with the effect of three symptom cluster subgroups on outcomes. Univariate and multivariate logistic regression analyses were used to examine how different subgroups predict mortality at five years of follow-up. Single symptoms were also entered into logistic regression to examine the relationship between single symptoms and mortality. We also performed Cox proportional hazard regression to examine the relationship between mortality and different subgroups. Kaplan-Meier curves were created to display survival, according to symptom subgroups. A $p<0.05$ was considered statistically significant.

\section{Results}

\section{Cluster and sample characteristics for subgroups}

From a sample size of 597, a three-cluster solution emerged. With the two-cluster solution, $64.2 \%$ of the sample $(n=383)$ was categorised in the 'all low' subgroup and $35.8 \%(n=214)$ in the 'all high' subgroup (Fig. 1). With the three-cluster solution, the 'all low' subgroup was divided into two groups, which were 'all low group' $(n=192,32.3 \%)$ and 'moderate' subgroup ( $n=191$, $32 \cdot 0 \%)$ and 'all high' subgroup $(n=214,35 \cdot 8 \%)$ (Fig. 1$)$.

Standardised symptom scores for each subgroup (Fig. 2) show the relatively high level of symptom scores in subgroup 3 compared with subgroups 1 and 2. Moderate symptom scores are shown in subgroup 2 .

Table 1 presents symptom scores for the three subgroups. Participants in subgroup 3 had worse dyspnoea, anxiety, depression and fatigue than those in subgroup 1. All post hoc analyses that compared symptom scores among the three subgroups were statistically significant (Table 1 ).

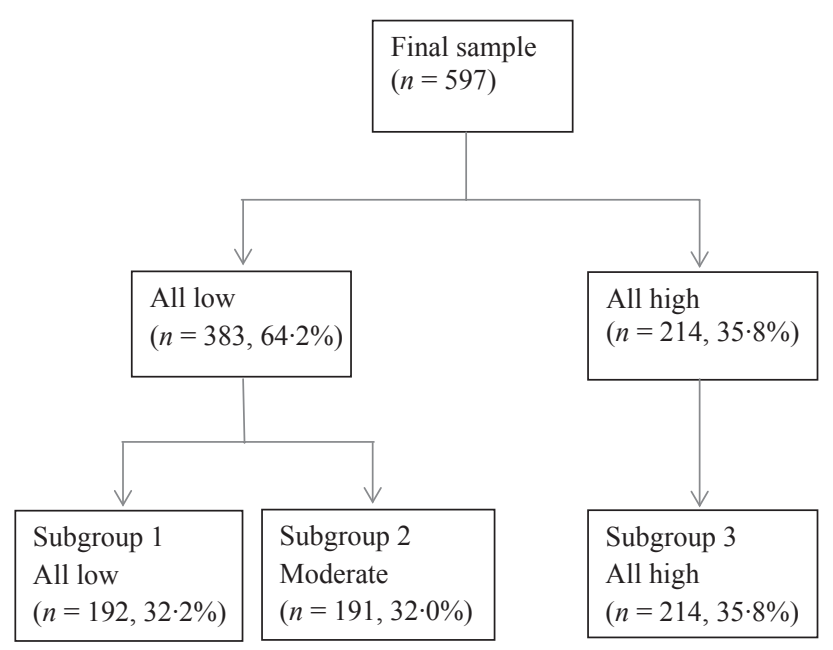

Figure 1 Flow chart for three subgroups. 


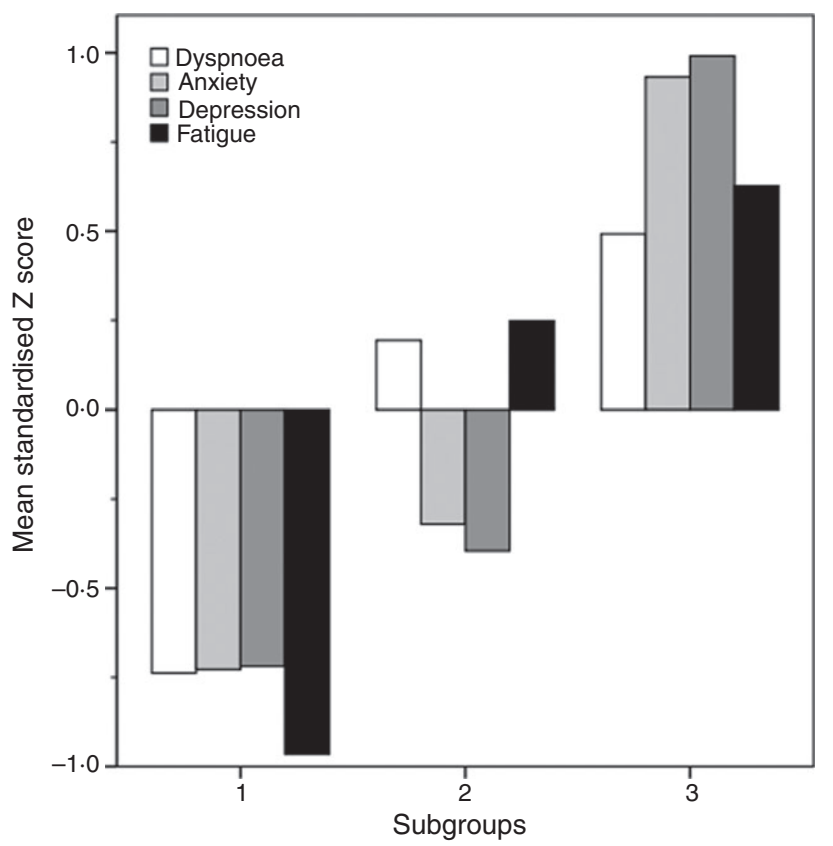

Figure 2 Standardised symptom scores for the three subgroups.

Demographic and clinical characteristics (mean age, proportion of higher education and proportion of oxygen use at rest and during sleep) were significantly different between subgroups (Table 2). Significant differences in FEV1\% predicted, forced vital capacity (FVC)\% predicted, diffusion capacity of carbon monoxide (DLCO)\% predicted, $\mathrm{PaCO}_{2}$, peak workload on the cycle ergometer and MOS-36 mental and physical component scales were found between subgroups (Table 2).

\section{Symptom clusters and healthcare use}

ANOVA results showed no difference in the mean number of nights spent in a hospital or other acute care facility or in a nonacute care facility and no difference in the number of visits to an $\mathrm{ED}$, triage or urgent care facility or to a physician assistant, nurse or outpatient clinic between subgroups (Table 2). However, Poisson regression analysis showed that subgroup 3 was more likely to spend more nights in a hospital or other acute care facility or in a nonacute care facility and had more visits to a physician assistant, nurse or outpatient clinic than subgroup 1 , even after adjusting for other covariates (Table 3 ). When analysed by single symptoms, those with high levels of anxiety, depression or fatigue used similar healthcare resources as subgroup 3 (Table 3 ).

\section{Symptom clusters and mortality}

Chi-square tests showed that mortality at five-year followup was highest in subgroup 3 (Table 2). In univariate and

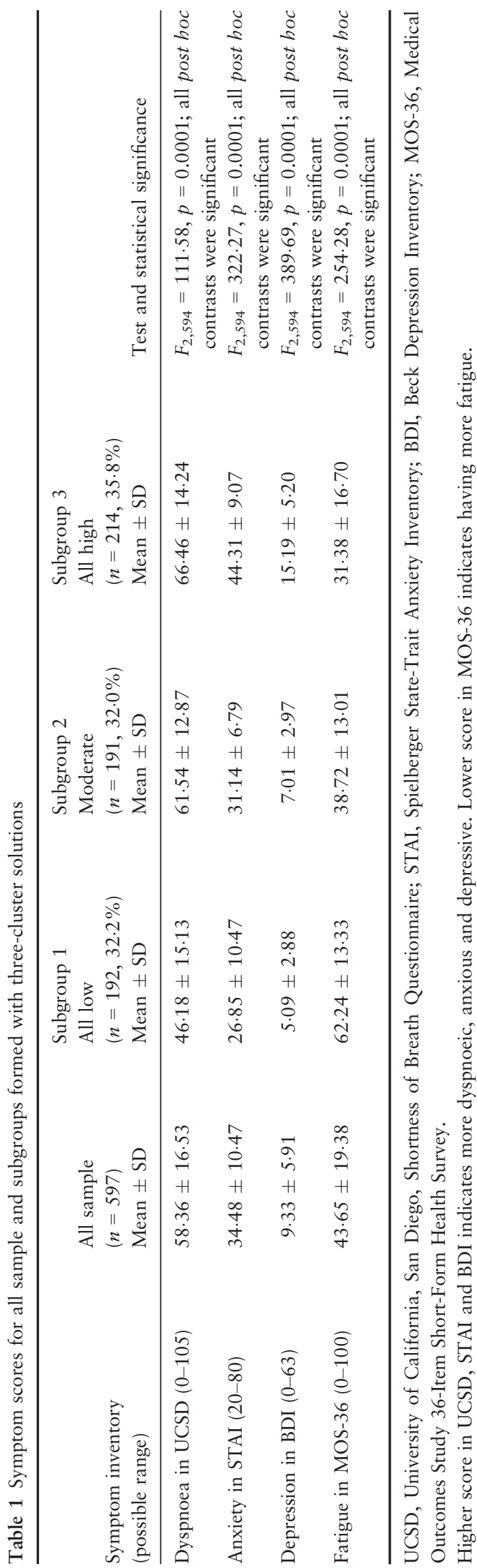




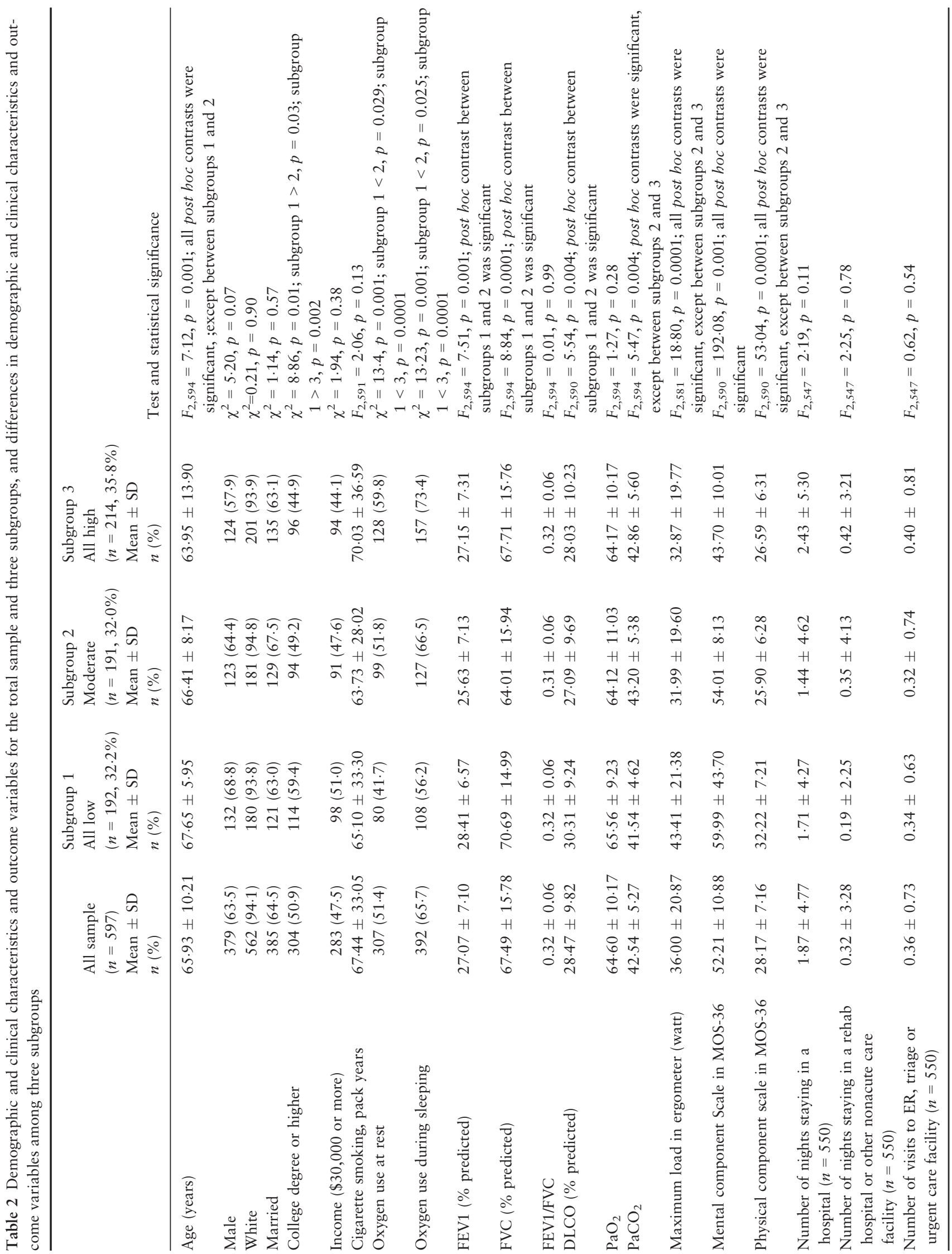




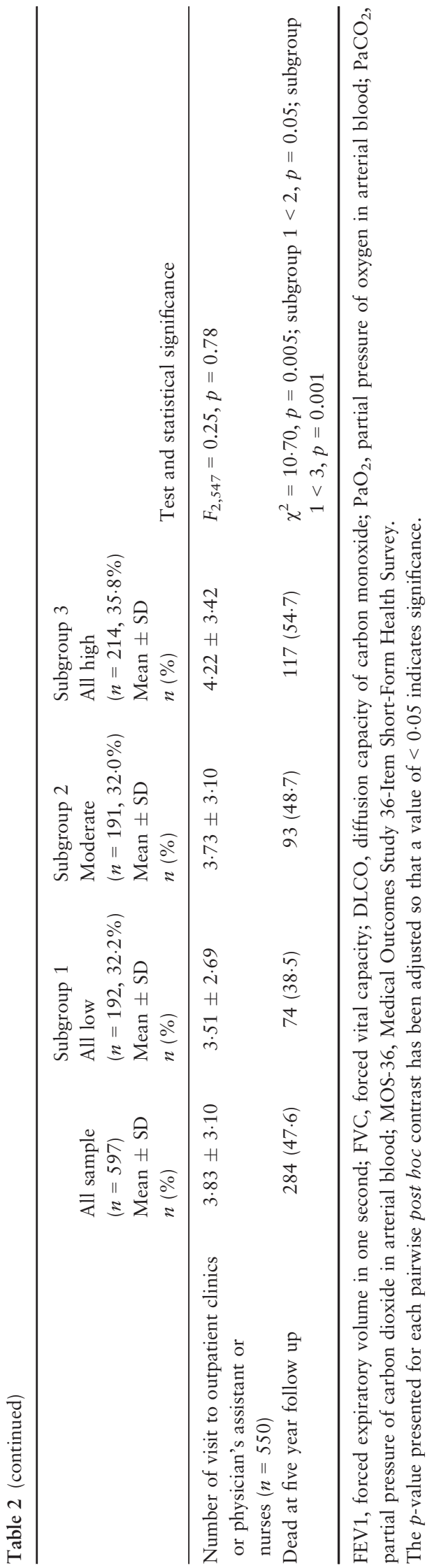

multivariate logistic regression, participants in subgroup 3 were more likely to have died by the five-year follow-up than participants in subgroups 1 and 2 (Table 4). When analysed by single symptoms, those with severe dyspnoea or depression were more likely to have died by the five-year follow-up (Table 4). Univariate Cox proportional hazards regression analyses were performed, but no statistical significance was observed in the survival pattern among subgroups. Kaplan-Meier curves presented to display differences in survival at five-year follow-up, according to symptom subgroups (Fig. 3).

\section{Discussion}

To our knowledge, this is the first study to examine the relationship of symptom clusters with healthcare use and mortality in people with COPD. It provides preliminary evidence that high levels of symptoms significantly predicted healthcare use and mortality in people with severe COPD. Those with high levels of symptoms, particularly high levels of anxiety and depression (subgroup 3), were young, less educated, used oxygen in their daily lives and had severe COPD, worse exercise capacity and poor quality of life. Symptom cluster subgroups had more significant relationship with mortality than single symptoms.

Symptom clusters have not been examined extensively in people with COPD. Previously, the primary author (Park et al. 2013) examined symptom clusters and the relationship of high symptom burden to outcomes of functional status and exercise capacity. In that analysis, we observed two symptom clusters, high and low. Participants with high levels of symptoms, especially fatigue, were young and less educated and had worse outcomes. In the current study, three distinct subgroups emerged, and the difference in the number of subgroups is because a different method for cluster analysis was used and healthcare use and mortality have a different relationship with symptoms. Those with high levels of symptoms, especially high levels of anxiety and depression, had worse outcomes. A high prevalence of anxiety and depression in people with COPD is well known and has been reported to be $50-75$ and $37-71 \%$, respectively (Solano et al. 2006). Anxiety and depression often occur together in people with breathing problem (Kunik et al. 2005). This finding further emphasises that screening for the presence and levels of anxiety and depression is necessary for people with COPD.

Few demographic characteristics differed among subgroups. People in subgroup 3 were younger than people in subgroup 1. This is consistent with another study that found that older people had less symptom distress than 
Table 3 Incidence rate ratio (95\% CI) for association of symptom clusters and single symptom with number of healthcare use within 10 months

\begin{tabular}{|c|c|c|c|c|}
\hline & $\begin{array}{l}\text { Number of nights } \\
\text { staying in a hospital }\end{array}$ & $\begin{array}{l}\text { Number of nights } \\
\text { staying in a rehab } \\
\text { hospital or other } \\
\text { nonacute care facility }\end{array}$ & $\begin{array}{l}\text { Number of visits to } \\
\text { ER, triage or urgent } \\
\text { care facility }\end{array}$ & $\begin{array}{l}\text { Number of visits to } \\
\text { outpatient clinics or } \\
\text { physician's assistant } \\
\text { or nurses }\end{array}$ \\
\hline \multicolumn{5}{|c|}{ Symptom cluster } \\
\hline \multicolumn{5}{|c|}{ Unadjusted model } \\
\hline Subgroup 1 & 1 & 1 & 1 & 1 \\
\hline Subgroup 2 & $0.84 *(0.71-0.99)$ & $1 \cdot 86^{*}(1 \cdot 23-2 \cdot 83)$ & $0.96(0.67-1.37)$ & $1.06(0.95-1.19)$ \\
\hline Subgroup 3 & $1.43 *(1.23-1.64)$ & $2 \cdot 25 *(1 \cdot 50-3 \cdot 35)$ & $1.19(0.85-1.66)$ & $1 \cdot 20 *(1 \cdot 08-1 \cdot 34)$ \\
\hline \multicolumn{5}{|l|}{ Adjusted model ${ }^{\dagger}$} \\
\hline Subgroup 1 & 1 & 1 & 1 & 1 \\
\hline Subgroup 2 & $0.75 *(0.62-0.90)$ & $1.47(0.94-2.29)$ & $0.81(0.54-1.21)$ & $1.03(0.91-1.16)$ \\
\hline Subgroup 3 & $1 \cdot 22 *(1 \cdot 04-1.43)$ & $1 \cdot 90 *(1 \cdot 23-2 \cdot 93)$ & $0.98(0.67-1.44)$ & $1 \cdot 12 *(1 \cdot 00-1 \cdot 26)$ \\
\hline \multicolumn{5}{|l|}{ Dyspnoea $^{*}$} \\
\hline \multicolumn{5}{|c|}{ Unadjusted model } \\
\hline$\leq 51$ & 1 & 1 & 1 & 1 \\
\hline $52-65$ & $1 \cdot 70 *(1 \cdot 44-2 \cdot 01)$ & $1.06(0.96-1.19)$ & $1.33(0.93-1.91)$ & $1.07(0.96-1.19)$ \\
\hline$\geq 66$ & $1.66 *(1.41-1.95)$ & $0.96(0.87-1.07)$ & $1.26(0.89-1.79)$ & $0.96(0.87-1.07)$ \\
\hline \multicolumn{5}{|l|}{ Anxiety ${ }^{\ddagger}$} \\
\hline \multicolumn{5}{|c|}{ Unadjusted model } \\
\hline$\leq 26$ & 1 & 1 & 1 & 1 \\
\hline $27-36$ & $0.94(0.80-1 \cdot 11)$ & $1.28(0.84-1.94)$ & $1.29(0.90-1.85)$ & $1 \cdot 11(0.99-1.25)$ \\
\hline$\geq 37$ & $1 \cdot 24 *(1.06-1.45)$ & $1 \cdot 67 *(1 \cdot 12-2 \cdot 50)$ & $1.05(0.72-1.53)$ & $1 \cdot 19 *(1 \cdot 07-1 \cdot 33)$ \\
\hline \multicolumn{5}{|l|}{ Depression ${ }^{\star}$} \\
\hline \multicolumn{5}{|c|}{ Unadjusted model } \\
\hline$\leq 5$ & 1 & 1 & 1 & 1 \\
\hline $6-9$ & $0.51 *(0.42-0.61)$ & $0.92(0.60-1.41)$ & $0.86(0.59-1.24)$ & $0.96(0.85-1.07)$ \\
\hline$\geq 10$ & $1 \cdot 33 *(1 \cdot 16-1.53)$ & $1.49 *(1 \cdot 01-2 \cdot 22)$ & $1.14(0.81-1.59)$ & $1 \cdot 20 *(1 \cdot 09-1 \cdot 34)$ \\
\hline \multicolumn{5}{|l|}{ Fatigue ${ }^{\ddagger}$} \\
\hline \multicolumn{5}{|c|}{ Unadjusted model } \\
\hline$\geq 51$ & 1 & 1 & 1 & 1 \\
\hline $31-50$ & $0.92(0.79-1.07)$ & $0.73(0.44-1.19)$ & $0.84(0.59-1.19)$ & $1.03(0.93-1 \cdot 14)$ \\
\hline$\leq 30$ & $1.28 *(1 \cdot 10-1.49)$ & $3 \cdot 83 *(2 \cdot 61-5 \cdot 61)$ & $1.17(0.83-1.64)$ & $1 \cdot 28 *(1.15-1.42)$ \\
\hline
\end{tabular}

"p $<0.05$.

${ }^{\dagger}$ Covariates include age, gender, race, education level, income level, marital status, pack years of smoking, maximal workload in cycle ergometer, FEV1\% predicted, $\mathrm{PaCO}_{2}$, use of oxygen, physical component scale in MOS-36.

${ }^{*}$ Scores were from University of California, San Diego, Shortness of Breath Questionnaire, Spielberger State-Trait Anxiety Inventory, Beck Depression Inventory and vitality subscale in Medical Outcomes Study 36-Item Short-Form Health Survey.

For this analysis, we used cutpoints that divided the sample into three equal groups for each of the single symptoms.

All analyses were performed separately.

younger patients (Degner \& Sloan 1995, Kris \& Dodd 2004). It may reflect an age-related difference in the perception of illness and symptoms (Lazarus \& DeLongis 1983); older people might think of symptoms as predictable events. In our study, people with lower education reported higher levels of symptoms; this should concern healthcare providers because a low education level could influence self-care behaviours for symptom management. As for health-related quality of life, people in subgroup 3 had poor quality of life as measured by the mental component scale; this is reasonable because people in subgroup 3 expressed higher levels of anxiety and depression than other subgroups. This likely reflects an overlap in the measures of symptoms and health-related quality of life.

The observed relationship between symptoms and disease severity is complex. Subgroup 1 had lower disease severity reflected by many variables, but the differences between subgroups were small especially for pulmonary function tests. Bigger differences were seen for the percentage using supplemental oxygen, scores on the MOS-36 physical component and exercise capacity. The difference in their exercise capacity, subgroup 1 compared to subgroups 2 and 3, was clinically meaningful (Lacasse et al. 1996). In contrast, participants in subgroups 2 and 3 had relatively similar 
Table 4 Odds ratios (OR) for association of symptom cluster and single symptom with five-year mortality from unadjusted and covariate-adjusted logistic regression modelling

\begin{tabular}{|c|c|c|}
\hline & \multicolumn{2}{|l|}{ Five-year mortality } \\
\hline & Unadjusted OR $(95 \% \mathrm{CI})$ & ${ }^{\dagger}$ Adjusted OR $(95 \%$ CI $)$ \\
\hline \multicolumn{3}{|c|}{ Symptom cluster } \\
\hline Subgroup 1 & 1 & 1 \\
\hline Subgroup 2 & $1 \cdot 51 *(1 \cdot 01-2 \cdot 27)$ & $1.27(0.82-1.99)$ \\
\hline Subgroup 3 & $1.92 *(1 \cdot 29-2 \cdot 86)$ & $1.75 *(1 \cdot 12-2 \cdot 74)$ \\
\hline \multicolumn{3}{|l|}{ Dyspnoea $^{*}$} \\
\hline$\leq 51$ & 1 & \\
\hline $52-65$ & $1 \cdot 35(0.90-2 \cdot 03)$ & \\
\hline$\geq 66$ & $1.87 *(1.26-2.79)$ & \\
\hline \multicolumn{3}{|l|}{ Anxiety } \\
\hline$\leq 26$ & 1 & \\
\hline $27-36$ & $1.08(0.71-1.63)$ & \\
\hline$\geq 37$ & $1.33(0.88-2 \cdot 01)$ & \\
\hline \multicolumn{3}{|l|}{ Depression* } \\
\hline$\leq 5$ & 1 & \\
\hline $6-9$ & $1.40(0.91-2 \cdot 13)$ & \\
\hline$\geq 10$ & $1 \cdot 90 *(1 \cdot 28-2 \cdot 84)$ & \\
\hline \multicolumn{3}{|l|}{ Fatigue } \\
\hline$\geq 51$ & 1 & \\
\hline $31-50$ & $1.01(0.69-1.48)$ & \\
\hline$\leq 30$ & $1.29(0.86-1.95)$ & \\
\hline
\end{tabular}

$* p<0.05$.

${ }^{\dagger}$ Covariates include age, gender, race, education level, income level, marital status, pack years of smoking, FEV1\% predicted, $\mathrm{PaCO}_{2}$, physical component scale in MOS-36 and number of healthcare use. ${ }^{*}$ Scores were from University of California, San Diego, Shortness of Breath Questionnaire, Spielberger State-Trait Anxiety Inventory, Beck Depression Inventory and vitality subscale in Medical Outcomes Study 36-Item Short-Form Health Survey.

For this analysis, we used cutpoints that divided the sample into three equal groups for each of the single symptoms.

All analyses were performed separately.

disease severity, but subgroup 3 reported more severe symptoms, especially anxiety and depression. This finding suggests that the relationship between symptoms and disease severity is not linear. It appears that as lung function declines, there reaches a point at which people respond differently in terms of their symptom experience. Some experience a muted response with relatively low levels of dyspnoea and fatigue, whereas others experience more intense dyspnoea and fatigue that is accompanied by the emotional responses of anxiety and depression. The underlying mechanisms that account for the differences in response are not clear, but the difference in symptom burden does have implications for quality of life.

It is well known that the cost of hospital care for people with COPD is high (National Institutes of Health, National Heart, Lung, \& Blood Institute 2013). Many factors have

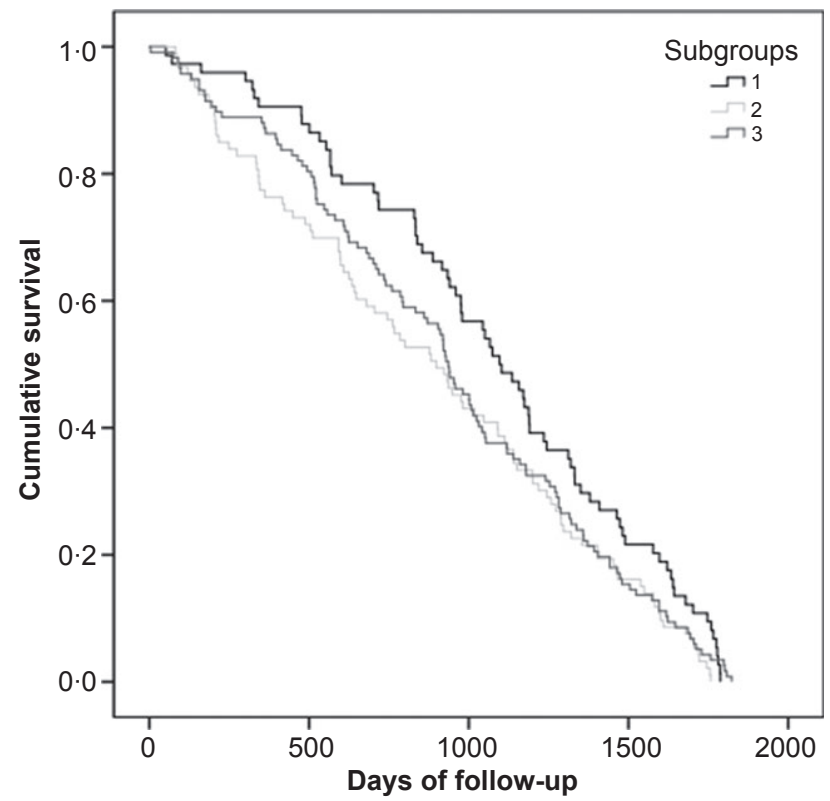

Figure 3 Kaplan-Meier curves of five-year survival according to symptom subgroups $(p=0.09)$.

been associated with healthcare use in people with COPD, such as age, body mass index, FEV1, history of hospital admission for COPD and quality of life (Almagro et al. 2006, Fan et al. 2007, Schembri et al. 2009). Single symptoms, especially dyspnoea, have also been significantly associated with healthcare use in people with COPD (Fan et al. 2007, Schembri et al. 2009, Papaioannou et al. 2013). Therefore, it is not surprising that clusters of high levels of symptoms were found to be significantly associated with healthcare use compared with low levels of symptoms. Our finding suggests that managing high levels of symptoms is necessary to decrease the need for health care in people with COPD.

Patients with advanced COPD in our study had significant mortality. Several factors have been associated with mortality in people with COPD, including single symptoms, low FEV1\% predicted, body mass index, marital status, age, oxygen use, lower total lung capacity, previous hospital admissions, pack years of smoking and quality of life (Almagro et al. 2002, Yohannes et al. 2002, Martinez et al. 2006, Esteban et al. 2008). It is important to note that subgroups 2 and 3 had a higher risk of mortality even after controlling for FEV1\% predicted and a wide range of demographic variables that are not modifiable. Symptom clusters are potentially modifiable factors. A better understanding of symptom clusters and their relationship to mortality may lead to effective interventions for more vigorous symptom management to reduce the mortality rate in people with COPD. 
The theory of unpleasant symptoms suggests that the effects of multiple symptoms may be synergistic (Lenz et al. 1997), but we did not find full support for this. We examined the relationship between single symptoms and outcomes and found that symptom cluster subgroups significantly predicted mortality more than single symptoms, but not with healthcare use. In previous research (Park et al. 2013), we examined the effect of single symptoms on other outcomes, such as functioning and exercise capacity in people with COPD. In that research, we found that symptom cluster subgroups showed a stronger association with social functioning than single symptoms, but not with physical functioning and exercise capacity. This indicates that the importance of symptom clusters may vary depending on the outcome of interest. Differences in techniques for forming clusters for single symptoms may also explain some of the observed differences in results. Thus, further study is required to test the theory of unpleasant symptoms in people with COPD.

The major strength of our study was its use of data from a well-designed randomised study, the NETT. As for its limitations, no data for comorbidity were available; however, some studies have shown no association between comorbidities and mortality (Esteban et al. 2008). In addition, we were unable to obtain the entire data for healthcare use over a 10-month period because the NETT had asked subjects about their healthcare use over the past month at five time periods, which may have overlooked healthcare use in the intervening months. Further, we were unable to obtain detailed information on the reasons for healthcare use: Was it COPD-related or not? Because information on hospital care was obtained through self-report, it may not be accurate. Finally, our findings may not be generalisable to people with mild-to-moderate COPD.

\section{Conclusion}

Three subgroup symptom clusters emerged from four symptoms. Our study indicates that the presence of high levels of symptoms in patients with COPD, especially high levels of anxiety and depression, was associated with healthcare use and mortality. Symptom cluster subgroups showed stronger association with mortality than single symptoms.
This finding suggests that assessing multiple symptoms rather than a single symptom is important to improve survival in people with COPD.

\section{Relevance to clinical practice}

Patients with high levels of symptoms require greater clinical attention. The assessment of coexisting symptoms should become part of an initial screening tool for patients with COPD. Self-monitoring of coexisting symptoms rather than just individual symptoms should be emphasised in teaching patients with COPD. Our findings should help healthcare providers identify patients with COPD who are at greater risk of adverse outcomes and who could benefit from an intervention whose aim is to lower hospital admission rates and mortality. Our findings also stress the importance of developing more effective symptom interventions for those with higher levels of symptoms to improve survival. Targeting modifiable symptoms within the cluster may be more beneficial than focusing on a single symptom to improve survival. Further study is needed to examine this finding in people who reflect the full range of COPD (mild to severe).

\section{Acknowledgements}

This manuscript was prepared using NETT Research Materials obtained from the NHLBI.

\section{Disclosure}

The authors have confirmed that all authors meet the ICMJE criteria for authorship credit (www.icmje.org/ethical_1author.html), as follows: (1) substantial contributions to conception and design of, or acquisition of data or analysis and interpretation of data; (2) drafting the article or revising it critically for important intellectual content; and (3) final approval of the version to be published.

\section{Conflict of interest}

None.

\section{References}

Aktas A, Walsh D \& Rybicki L (2010) Symptom clusters: myth or reality? Palliative Medicine 24, 373-385.

Almagro P, Calbo E, Ochoa de Echagüen A, Barreiro B, Quintana S, Heredia JL
\& Garau J (2002) Mortality after hospitalization for COPD. Chest 121, 1441-1448.

Almagro P, Barreiro B, Ochoa de Echaguen A, Quintana S, Rodríguez Carballe- ira M, Heredia JL \& Garau J (2006) Risk factors for hospital readmission in patients with chronic obstructive pulmonary disease. Respiration 73, 311-317. 
American Lung Association (2013) Trends in COPD (Chronic Bronchitis and Emphysema): Morbidity and Mortality. Available at: www.lungusa.org/finding_cures/our_research/trend_reports /copd_trend_report.pdf (assessed 7 July 2013).

American Thoracic Society (1995a) Singlebreath carbon monoxide diffusing capacity (transfer factor) Recommendations for a standard technique-1995 update. American Journal of Respiratory and Critical Care Medicine 152, 2185-2198.

American Thoracic Society (1995b) Standardization of spirometry, 1994 update. American Journal of Respiratory and Critical Care Medicine 152, 1107-1136.

Beck AT \& Steer RA (1993) BDI: Beck Depression Inventory Manual. Psychological Corporation, New York, NY.

Blinderman CD, Homel P, Billings JA, Tennstedt S \& Portenoy RK (2009) Symptom distress and quality of life in patients with advanced chronic obstructive pulmonary disease. Journal of Pain and Symptom Management 38, 115-123.

Cheville AL, Novotny PJ, Sloan JA, Basford JR, Wampfler JA, Garces YI, Jatoi A \& Yang P (2011) The value of a symptom cluster of fatigue, dyspnea, and cough in predicting clinical outcomes in lung cancer survivors. Journal of Pain and Symptom Management 42, 213-221.

Covey MK, Larson JL \& Wirtz S (1999) Reliability of submaximal exercise tests in patients with COPD. Medicine and Science in Sports and Exercise 31, 1257-1264.

Crapo RO \& Morris AH (1981) Standardized single breath normal values for carbon monoxide diffusing capacity. American Review Respiratory Disease 123, 185-189.

Crapo RO, Morris AH \& Gardner RM (1981) Reference spirometric values using techniques and equipment that meet ATS recommendations. American Review Respiratory Disease 123, 659-664.

Dahlén I \& Janson C (2002) Anxiety and depression are related to the outcome of emergency treatment in patients with obstructive pulmonary disease. Chest 122, 1633-1637.
Degner LF \& Sloan JA (1995) Symptom distress in newly diagnosed ambulatory cancer patients and as a predictor of survival in lung cancer. Journal of Pain and Symptom Management 10, 423-431.

Eakin EG, Resnikoff PM, Prewitt LM, Ries AL \& Kaplan RM (1998) Validation of a new dyspnea measure: the UCSD shortness of breath questionnaire, University of San Diego. Chest 113, 619-624.

Esteban C, Quintana JM, Aburto M, Moraza J, Egurrola M, España PP, Pérez-Izquierdo J \& Capelastegui A (2008) Predictors of mortality in patients with stable COPD. Journal of General Internal Medicine 23, 1829-1834.

Fan VS, Ramsey SD, Giardino ND, Make BJ, Emery CF, Diaz PT, Benditt JO, Mosenifar Z, McKenna R Jr, Curtis JL, Fishman AP \& Martinez FJ; National Emphysema Treatment Trial (NETT) Research Group (2007) Sex, depression, and risk of hospitalization and mortality in chronic obstructive pulmonary disease. Archives Internal Medicine 167, 2345-2353.

Figarska SM, Boezen HM \& Vonk JM (2012) Dyspnea severity, changes in dyspnea status and mortality in the general population: the Vlagtwedde/ Vlaardingen study. European Journal of Epidemiology 27, 867-876.

Fishman A, Martinez F, Naunheim K, Piantadosi S, Wise R, Ries A, Weinmann G \& Wood DE (2003) A randomized trial comparing lung-volume-reduction surgery with medical therapy for severe emphysema. New England Journal of Medicine 348, 2059-2073.

Ford ES, Croft JB, Mannino DM, Wheaton AG, Zhang X \& Giles WH (2013) COPD Surveillance-United States, 1999-2011. Chest 144, 284-305.

Foster TS, Miller JD, Marton JP, Caloyeras JP, Russell MW \& Menzin J (2006) Assessment of the economic burden of COPD in the U.S.: a review and synthesis of the literature. Journal of Chronic Obstructive Pulmonary Disease 3, 211-218.

Fountoulakis KN, Bech P, Panagiotidis P, Siamouli M, Kantartzis S, Papadopoulou A, Papadopoulou M, Kaprinis S, Kourila E, Iacovides A \& St Kaprinis G (2007) Comparison of depressive indices: reliability, validity, relation- ship to anxiety and personality and the role of age and life events. Journal of Affective Disorders 97, 187-195.

Harel D, Thombs BD, Hudson M, Baron M \& Steele R; Canadian Scleroderma Research Group (2012) Measuring fatigue in SSc: a comparison of the Short Form-36 Vitality subscale and Functional Assessment of Chronic Illness Therapy-Fatigue scale. Rheumatology 51, 2177-2185.

Hewlett S, Dures E \& Almeida C (2011) Measures of fatigue: Bristol Rheumatoid Arthritis Fatigue Multi-Dimensional Questionnaire (BRAF MDQ), Bristol Rheumatoid Arthritis Fatigue Numerical Rating Scales (BRAF NRS) for severity, effect, and coping, Chalder Fatigue Questionnaire (CFQ), Checklist Individual Strength (CIS20R and CIS8R), Fatigue Severity Scale (FSS), Functional Assessment Chronic Illness Therapy (Fatigue) (FACIT-F), Multi-Dimensional Assessment of Fatigue (MAF), Multi-Dimensional Fatigue Inventory (MFI), Pediatric Quality Of Life (PedsQL) Multi-Dimensional Fatigue Scale, Profile of Fatigue (ProF), Short Form 36 Vitality Subscale (SF-36 VT), and Visual Analog Scales (VAS). Arthritis Care \& Research 63, S263-S286.

Hwang SY, Ahn YG \& Jeong MH (2012) Atypical symptom cluster predicts a higher mortality in patients with first-time acute myocardial infarction. Korean Circulation Journal 42, 16 22.

Jain NC, Indrayan A \& Goel LR (1986) Monte carlo comparison of six hierarchical clustering methods on random data. Pattern Recognition 19, 95-99.

Kalichman SC, Rompa D \& Cage M (2000) Distinguishing between overlapping somatic symptoms of depression and HIV disease in people living with HIV-AIDS. Journal of Nervous and Mental Disease 188, 662-670.

Ketchen DJ \& Shook CL (1996) The application of cluster analysis in strategic management research: an analysis and critique. Strategic Management Journal 17, 441-458.

Kim HJ, McGuire DB, Tulman L \& Barsevick AM (2005) Symptom clusters: concept analysis and clinical implications for cancer nursing. Cancer Nursing 28, 270-282. 
Kris AE \& Dodd MJ (2004) Symptom experience of adult hospitalized medicalsurgical patients. Journal of Pain and Symptom Management 28, 451-459.

Kunik ME, Roundy K, Veazey C, Souchek J, Richardson P, Wray NP \& Stanley MA (2005) Surprisingly high prevalence of anxiety and depression in chronic breathing disorders. Chest 127, 1205-1211.

Lacasse Y, Wong E, Guyatt GH, King D, Cook DJ \& Goldstein RS (1996) Meta-analysis of respiratory rehabilitation in chronic obstructive pulmonary disease. Lancet 348, 1115-1119.

Lazarus RS \& DeLongis A (1983) Psychological stress and coping in aging. The American Psychologists 38, 245-254.

Lee KS, Song EK, Lennie TA, Frazier SK, Chung ML, Heo S, Wu JR, Rayens MK, Riegel B \& Moser DK (2010) Symptom clusters in men and women with heart failure and their impact on cardiac event-free survival. Journal of Cardiovascular Nursing 25, 263 272.

Lenz ER, Pugh LC, Milligan RA, Gift A \& Suppe F (1997) The middle-range theory of unpleasant symptoms: an update. Advances in Nursing Science 19, 14-27.

Lundbäck B, Eriksson B, Lindberg A, Ekerljung L, Muellerova H, Larsson LG \& Rönmark E (2009) A 20-year follow-up of a population study-based COPD cohort-report from the obstructive lung disease in Northern Sweden studies. Journal of Chronic Obstructive Pulmonary Disease 6, 263-271.

Mannino DM, Buist AS, Petty TL, Enright PL \& Redd SC (2003) Lung function and mortality in the United States: data from the First National Health and Nutrition Examination Survey follow up study. Thorax 58, 388-393.

Martinez FJ, Foster G, Curtis JL, Criner G, Weinmann G, Fishman A, DeCamp MM, Benditt J, Sciurba F, Make B, Mohsenifar Z, Diaz P, Hoffman E \& Wise R; NETT Research Group (2006) Predictors of mortality in patients with emphysema and severe airflow obstruction. American Journal of Respiratory and Critical Care Medicine 173, 1326-1334.

McHorney CA, Ware JE Jr \& Raczek AE (1993) The MOS 36-item short-from health survey (SF-36): II. Psychometric and clinical tests of validity in measuring physical and mental health constructs. Medical Care 31, 247-263.

McHorney CA, Ware JE Jr, Lu JF \& Sherbourne CD (1994) The MOS 36-item short-from health survey (SF-36): III. Tests of data quality, scaling assumptions, and reliability across diverse patient groups. Medical Care 32, 4066.

Miaskowski C, Cooper BA, Paul SM, Dodd M, Lee K, Aouizerat BE, West C, Cho M \& Bank A (2006) Subgroups of patients with cancer with different symptom experiences and quality of life outcomes: a cluster analysis. Oncology Nursing Forum 33, E79-E89.

Miniño AM, Xu JQ \& Kochanek KD (2010) Deaths: Preliminary Data For 2008. National Vital Statistics Reports; Vol 59 No.2. National Center for Health Statistics, Hyattsville, MD.

Motl RW \& McAuley E (2009) Symptom cluster as a predictor of physical activity in multiple sclerosis: preliminary evidence. Journal of Pain and Symptom Management 38, 270-280.

National Emphysema Treatment Trial Research Group (1999) Rationale and design of the National Emphysema Treatment Trial: a prospective randomized trial of lung volume reduction surgery. Chest 116, 1750-1761.

National Emphysema Treatment Trial Research Group (2003) A randomized trial comparing lung-volume-reduction surgery with medical therapy for severe emphysema. New England Journal of Medicine 348, 2059-2073.

National Institutes of Health, National Heart, Lung, and Blood Institute (2013) Morbidity \& Mortality: 2009 Chart Book on Cardiovascular, Lung, and Blood Diseases. Available at: http://www.nhlbi.nih.gov/resources/ docs/2009_chartbook.pdf (assessed 7 July 2013).

Ng TP, Niti M, Tan WC, Cao Z, Ong KC \& Eng P (2007) Depressive symptoms and chronic obstructive pulmonary disease: effect on mortality, hospital readmission, symptom burden, functional status, and quality of life. Archives Internal Medicine 167, 6067.

Nishimura K, Izumi T, Tsukino M \& Oga $\mathrm{T}$ (2002) Dyspnea is a better predictor of 5-year survival than airway obstruction in patients with COPD. Chest 121, 1434-1440.

Papaioannou AI, Bartziokas K, Tsikrika S, Karakontaki F, Kastanakis E, Banya W, Haniotou A, Papiris S, Loukides S, Polychronopoulos V \& Kostikas K (2013) The impact of depressive symptoms on recovery and outcome of hospitalised COPD exacerbations. European Respiratory Journal 41, 815-823.

Park SK, Stotts NA, Douglas MK, Donesky-Cuenco D \& Carrieri-Kohlman V (2012) Symptoms and functional performance in Korean immigrants with asthma or chronic obstructive pulmonary disease. Heart and Lung 41, 226-237.

Park SK, Meldrum C \& Larson JL (2013) Subgroup analysis of symptoms and their effect on functioning, exercise capacity, and physical activity in patients with severe chronic obstructive pulmonary disease. Heart and Lung 42, 465-472.

Riegel B, Hanlon AL, McKinley S, Moser DK, Meischke H, Doering LV, Davidson P, Pelter MM \& Dracup K (2010) Differences in mortality in acute coronary syndrome symptom clusters. American Heart Journal 159, 392-398.

Schembri S, Anderson W, Morant S, Winter J, Thompson P, Pettitt D, MacDonald TM \& Winter JH (2009) A predictive model of hospitalization and death from chronic obstructive pulmonary disease. Respiratory Medicine 103, 1461-1467.

Söderman P \& Malchau H (2000) Validity and reliability of Swedish WOMAC osteoarthritis index: a self-administered disease-specific questionnaire (WOMAC) versus generic instruments (SF-36 and NHP). Acta Orthopaedica Scandinavica 71, 39-46.

Solano JP, Gomes B \& Higginson IJ (2006) A comparison of symptom prevalence in far advanced cancer, AIDS, heart disease, chronic obstructive pulmonary disease and renal disease. Journal of Pain and Symptom Management 31, 58-69.

Spielberger CD, Gorsuch RL, Lushene R, Vagg PR \& Jacobs GA (1983) Manual for State-Trait Anxiety Inventory. Consulting Psychologists Press, Palo Alto, CA. 
Stage KB, Middelboe T \& Pisinger C (2005) Depression and chronic obstructive pulmonary disease (COPD). Impact on survival. Acta Psychiatrica Scandinavica 111, 320-323.

de Voogd JN, Wempe JB, Koëter GH, Postema K, van Sonderen E, Ranchor AV, Coyne JC \& Sanderman R (2009)
Depressive symptoms as predictors of mortality in patients with COPD. Chest 135, 619-625.

Yohannes AM, Baldwin RC \& Connolly M (2002) Mortality predictors in disabling chronic obstructive pulmonary disease in old age. Age and Ageing 31, 137-140.
Yohannes AM, Baldwin RC \& Connolly MJ (2005) Predictors of 1-year mortality in patients discharged from hospital following acute exacerbation of chronic obstructive pulmonary disease. Age and Ageing 34, 491496.

The Journal of Clinical Nursing (JCN) is an international, peer reviewed journal that aims to promote a high standard of clinically related scholarship which supports the practice and discipline of nursing.

For further information and full author guidelines, please visit JCN on the Wiley Online Library website: http:// wileyonlinelibrary.com/journal/jocn

\section{Reasons to submit your paper to JCN:}

High-impact forum: one of the world's most cited nursing journals, with an impact factor of 1.316 - ranked 21/101 (Nursing (Social Science)) and 25/103 Nursing (Science) in the 2012 Journal Citation Reports ${ }^{\circledR}$ (Thomson Reuters, 2012).

One of the most read nursing journals in the world: over 1.9 million full text accesses in 2011 and accessible in over 8000 libraries worldwide (including over 3500 in developing countries with free or low cost access).

Early View: fully citable online publication ahead of inclusion in an issue.

Fast and easy online submission: online submission at http://mc.manuscriptcentral.com/jcnur.

Positive publishing experience: rapid double-blind peer review with constructive feedback.

Online Open: the option to make your article freely and openly accessible to non-subscribers upon publication in Wiley Online Library, as well as the option to deposit the article in your preferred archive. 